\title{
Evolution of Mammalian KELL Blood Group Glycoproteins and Genes (KEL): Evidence for a Marsupial Origin from an Ancestral M13 Type II Endopeptidase Gene
}

\section{Roger S Holmes*}

Eskitis Institute for Drug Discovery and School of Biomolecular and Physical Sciences, Griffith University, Nathan, QLD, Australia

\begin{abstract}
KELL is a member of the M13 family of type II neutral endopeptidases, which functions as a blood group antigen in human and animal populations. KELL amino acid sequences and structures and KEL gene locations were examined using bioinformatic data from several mammalian genome projects. Mammalian KELL sequences shared $55-99 \%$ identity, as compared with $21-31 \%$ sequence identities with other M13-like family members. Four predicted $\mathrm{N}$-glycosylation sites were conserved among the mammalian KELL proteins examined. Sequence alignments, key amino acid residues and conserved predicted secondary and tertiary structures were also studied, including active site residues, predicted disulfide forming Cys residues, cytoplasmic, transmembrane and extracellular sequences and KELL C-terminus amino acid sequences. Mammalian KEL genes usually contained 18 or 19 coding exons on the direct strand. Transcription factor binding sites within the human $K E L$ promoter may regulate transcription within erythroid cells. Phylogenetic analyses examined the relationships and potential evolutionary origins of the mammalian KEL gene with six other vertebrate neutral endopeptidase M13 family genes. These suggested that $K E L$ originated in an ancestral marsupial genome from a gene duplication event of a neutral endopeptidase M13-like gene.
\end{abstract}

Keywords: KELL glycoproteins; Blood group antigens; KEL; Sequence conservation; Marsupial origin; Gene evolution

Abbreviations: KELL: Blood Group Glycoprotein; KEL: KELL Blood
Group Glycoprotein Gene; MME: Membrane Metallo-Endopeptidase;
ECE: Endothelin-Converting Enzyme; PHEX: Phosphate Regulating
Neutral Endopeptidase; ECEL1: ECE-Like Protein 1; RBC: Red Blood
Cell; XY protein: A Multipass Membrane Protein; QTL: Quantitative
Trait Locus; BLAST: Basic Local Alignment Search Tool; BLAT:
Blast-Like Alignment Tool; NCBI: National Center for Biotechnology
Information; KO: Knock Out; AceView: NCBI Based Representation
of Public mRNAs; SWISS-MODEL: Automated Protein Structure
Homology-Modeling Server; UTR: Untranslated Gene Region

\section{Introduction}

KELL blood group glycoprotein (KELL, also called CD antigen 238; EC 3.4.24.-) is one of at least seven members of the M13 family of neutral endopeptidases, which are zinc-containing type II transmembrane enzymes [1-4]. KELL blood group glycoprotein contains several antigens that are highly immunogenic and serve as the third most effective system in triggering an immune reaction, after the $\mathrm{ABO}$ and $\mathrm{Rh}$ blood groups [5-7]. KELL is also a single-pass transmembrane protein which is linked to the XY protein, found in red blood cell (RBC) membranes [8,9], and serves as an endothelinconverting enzyme, an endopeptidase which cleaves 'big' endothelin-3 to form an active vasoconstrictor peptide $[10,11]$.

Other M13 neutral endopeptidases have been described: Membrane endopeptidase (MME) or neprilysin (NEP) inactivates signaling peptides involved in regulating blood pressure, the immune system and neuronal activity [12-14]; membrane metallo-endopeptidaselike 1 (MMEL1) or neprilysin-like protein 1 (NEPL1), reported as a susceptibility locus for multiple sclerosis, primary biliary cirrhosis and rheumatoid arthritis with a proposed sperm function role [15-18]; endothelin-converting enzyme 1 (ECE1, EC=3.4.24.71) $[19,20]$, and endothelin-converting enzyme 2 (ECE2, EC=3.4.24.71) participate in regulatory peptide processing $[21,22]$; endothelin-converting enzymelike 1 (ECEL1) serves an essential role in the nervous control of respiration $[23,24]$; and phosphate-regulating neutral endopeptidase (PHEX), which is involved in bone mineralization, and has a proposed role in renal phosphate reabsorption $[25,26]$.
The gene encoding KELL (KEL in humans; Kel in mice) is highly expressed in erythroid tissues, but also in other tissues, including testis, heart, spleen and skeletal muscle [3,9]. The structures of the human KEL and the mouse Kel genes have been reported, containing 18 or 19 exons of DNA encoding KELL sequences $[9,10,27,28]$. The molecular basis of the major human KELL antigens has been determined, which result from KEL point mutations and single amino acid substitutions [29]. At least $30 \mathrm{KELL}$ antigens are reported [27,30,31], including the highest frequency $K E L$ polymorphism in human populations, designated as $\mathrm{K}_{1} /$ $\mathrm{K}_{2}$, due to a $\mathrm{C} \rightarrow \mathrm{T}$ substitution in exon 6 causing a $193 \mathrm{Thr}$ to $193 \mathrm{Met}$ substitution and disruption of an N-glycosylation site [32]. Other high incidence KELL antigens have been reported, including KALT, which is sensitive to treatment of RBCs by trypsin [27,33]. A 'null' human KEL phenotype (designated as $\mathrm{K}_{0}$ ), which abolishes KELL expression in erythroid tissues, resulting from a mutation at the splicing exon 3 donor site [33], while other $\mathrm{K}_{0}$ alleles have been reported in low frequency in a Chinese population [34]. Knock-out (Kel-/Kel-) (KO) mice lacking RBC KELL glycoprotein exhibited changes in red cell ion transport and some mild motor dysfunction, have provided a useful model to study the biochemical and physiological roles for this protein [31]. RBC Gardos channel activity, which normally functions as a potassium chloride cotransport and calcium-activated potassium channel, and assists with maintaining RBC hydration status [34], was increased in $\mathrm{KO}$ erythrocytes, although lacking endothelin-converting endopeptidase activity. Antibodies generated in the circulation system in response to KELL antigens are usually immunoglobulin $\mathrm{G}$, which

*Corresponding author: Roger S Holmes, Eskitis Institute for Drug Discovery School of Biomolecular and Physical Sciences, Griffith University, Nathan, QLD 4111, Australia, Tel: +61 7 37356008; E-mail: r.holmes@griffith.edu.au

Received April 14, 2013; Accepted July 17, 2013; Published July 22, 2013

Citation: Holmes RS (2013) Evolution of Mammalian KELL Blood Group Glycoproteins and Genes (KEL): Evidence for a Marsupial Origin from an Ancestral M13 Type II Endopeptidase Gene. J Phylogen Evolution Biol 1: 112 doi:10.4172/2329-9002.1000112

Copyright: (c) 2013 Holmes RS. This is an open-access article distributed under the terms of the Creative Commons Attribution License, which permits unrestricted use, distribution, and reproduction in any medium, provided the original author and source are credited. 
Citation: Holmes RS (2013) Evolution of Mammalian KELL Blood Group Glycoproteins and Genes (KEL): Evidence for a Marsupial Origin from an Ancestral M13 Type II Endopeptidase Gene. J Phylogen Evolution Biol 1: 112. doi:10.4172/2329-9002.1000112

Page 2 of 9

may result in severe hemolytic transfusion reactions and hemolytic disease of the fetus and newborn [5,7]. Recent studies have suggested that these reactions may occur not only as a result of immune RBC destruction, but also by the suppression of erythropoiesis by antiKELL- $\mathrm{K}_{1}$ antibodies, which can lead to severe anemia in the fetus or new born $[35,36]$.

This paper reports the predicted gene structures and amino acid sequences for several mammalian KEL genes and proteins, the predicted structures for mammalian KELL proteins and the structural, phylogenetic and evolutionary relationships for these genes and enzymes with those for six other vertebrate M13 neutral Type II endopeptidase gene families. The results suggest that the mammalian KEL gene arose from the duplication event of an ancestral mammalian M13 Type IIlike endopeptidase gene, with the appearance corresponding to the emergence of marsupial mammals during evolution.

\section{Methods}

\section{Mammalian KEL gene and KELL protein identification}

BLAST studies were undertaken using web tools from the National Center for Biotechnology Information (NCBI) [37]. Protein BLAST analyses used mammalian KELL and six other vertebrate M13 neutral endopeptidase amino acid sequences previously described $[1,2,9,23,38$ 43] (Table 1 and 2).

BLAT analyses were subsequently undertaken for each of the predicted KELL amino acid sequences and other M13 neutral endopeptidase-like genes, using the UC Santa Cruz Genome Browser with the default settings to obtain the predicted locations for each of these vertebrate genes, including predicted exon boundary locations and gene sizes (Table 1 and 2) [44]. The AceView website was used to obtain structures for the major human KEL and mouse Kel transcripts [28].

\section{Predicted structures and properties of mammalian KELL proteins}

Predicted secondary and tertiary structures for human and other mammalian KELL proteins were obtained using the SWISS-MODEL web-server [43], and the reported tertiary structure for human ECE1 complexed with phosphoramidon [20] (PDB:3dwbA), with a modeling residue range of 60-713 for human KELL. Molecular weights, $\mathrm{N}$-glycosylation sites and predicted transmembrane [46], cytosolic and extracellular sequences for mammalian KELL and related vertebrate M13 Type II endopeptidase proteins were obtained using Expasy web tools (http://au.expasy.org/tools/pi_tool.html). Identification of conserved domains for mammalian KELL proteins was made using NCBI web tools [47] (http://www.ncbi.nlm.nih.gov/Structure/cdd/ wrpsb.cgi).

\section{Comparative human (KEL) gene expression}

The genome browser (http://genome.ucsc.edu) was used to examine GNF Expression Atlas 2 data, using U133A and GNF1H expression chips for the human KEL gene (http://biogps.gnf.org) [48]. Gene array expression 'heat maps' were examined for comparative gene expression levels among human and mouse tissues, showing high (red); intermediate (black); and low (green) expression levels.

\section{Phylogeny studies and sequence divergence}

Phylogenetic analyses were undertaken using the http://phylogeny. fr platform [49]. Alignments of mammalian KELL sequences, six other vertebrate M13 neutral endopeptidase sequences and a nematode (Caenorhabditis elegans) M13 endopeptidase-like sequence were assembled using PMUSCLE [50] (Table 1 and 2). Alignment ambiguous regions were excluded prior to phylogenetic analysis, yielding alignments for mammalian KELL sequences with other vertebrate neutral endopeptidase and nematode (Caenorhabditis elegans) M13like sequences. The phylogenetic tree was constructed using the maximum liklihood tree estimation program PHYML [51].

\begin{tabular}{|c|c|c|c|c|c|c|c|c|c|c|c|c|c|c|}
\hline Gene KELL & Species & $\begin{array}{l}\text { RefSeq ID } \\
\text { 'EnsembI/NCBI }\end{array}$ & GenBank ID & $\begin{array}{l}\text { UNIPROT } \\
\text { ID }\end{array}$ & $\begin{array}{l}\text { Amino } \\
\text { Acids }\end{array}$ & Chromosome location & $\begin{array}{l}\text { Coding } \\
\text { Exons } \\
\text { (strand) }\end{array}$ & $\begin{array}{l}\text { Gene } \\
\text { Size bps }\end{array}$ & $\begin{array}{l}\text { Subunit } \\
\text { MW }\end{array}$ & $\begin{array}{l}\text { Gene } \\
\text { Expression }\end{array}$ & pl & $\begin{array}{l}\text { \% Identity } \\
\text { human } \\
\text { KELL }\end{array}$ & $\begin{array}{l}\text { \% Identity } \\
\text { human } \\
\text { ECE1 }\end{array}$ & $\begin{array}{l}\text { \% Identity } \\
\text { human MME }\end{array}$ \\
\hline $\begin{array}{l}\text { Human } \\
\text { (KELa) }\end{array}$ & Homo sapiens & NM_000420 & BC003135 & P23276 & 732 & 7:142,638,342-142,658,959 & $19(-\mathrm{ve})$ & 20,618 & 82,824 & 0.5 & 8.1 & 100 & 30 & 21 \\
\hline $\begin{array}{l}\text { Human } \\
\text { (KELb) }\end{array}$ & Homo sapiens & na & $\mathrm{CH} 471198$ & na & 713 & $7,142,638,342-142,659,588$ & $18(-\mathrm{ve})$ & 20,247 & 80,793 & na & 8.6 & 100 & 30 & 21 \\
\hline Chimp & Pan troglodytes & XP_519445 & na & na & 732 & $7: 144,486,459-144,507,070$ & $19(-\mathrm{ve})$ & 20,612 & 82,864 & na & 8.3 & 98 & 30 & 21 \\
\hline Gorilla & Gorilla gorilla & XP_004046423 & na & na & 732 & $7: 141,432,380-141,452,992$ & 19 (-ve) & 20,613 & 82,725 & na & 8.1 & 99 & 30 & 21 \\
\hline Gibbon & $\begin{array}{l}\text { Nomascus } \\
\text { leucogenys }\end{array}$ & XP_003270898 & na & na & 713 & *397332:328,035-330,342 & $18(-\mathrm{ve})$ & 20,308 & 80,743 & na & 7.9 & 96 & 31 & 22 \\
\hline Rhesus & Macaca mulatta & na & EHH17796 & na & 713 & $3: 182,467,328-182,487,814$ & $18(-\mathrm{ve})$ & 20,487 & 80,867 & na & 7.3 & 93 & 31 & 23 \\
\hline $\begin{array}{l}\text { Squirrel } \\
\text { monkey }\end{array}$ & Saimiri boliviensis & XP_003929965 & na & na & 713 & *378140:9,028,614-9,050,096 & $18(-\mathrm{ve})$ & 21,483 & 80,867 & na & 7.3 & 90 & 31 & 22 \\
\hline Mouse & Mus musculus & NM_032540 & BC099961 & Q9EQF2 & 713 & $6: 41,686,450-41,703,500$ & $18(-\mathrm{ve})$ & 17,051 & 80,866 & 0.8 & 5.9 & 74 & 31 & 22 \\
\hline Rat & Rattus norvegicus & NM_001191611 & na & na & 713 & 4:69,392,966-69,409,477 & $18(-\mathrm{ve})$ & 16,512 & 81,008 & 0.2 & 7.1 & 70 & 31 & 21 \\
\hline Pig & Sus scrofa & XP_003134648 & na & na & 730 & $18: 7,555,168-7,578,252$ & $18(-v e)$ & 23,085 & 82,077 & na & 6.4 & 69 & 30 & 23 \\
\hline Horse & Equus caballus & XP_001489752 & na & na & 713 & 4:96,015,434-96,034,243 & $18(-\mathrm{ve})$ & 18,810 & 80,732 & na & 7.9 & 77 & 31 & 23 \\
\hline Cow & Bos taurus & XP_001788561 & na & na & 721 & $4: 109,587,066-109,625,396$ & $18(-\mathrm{ve})$ & 38,331 & 81,503 & na & 8.1 & 67 & 31 & 19 \\
\hline Rabbit & $\begin{array}{l}\text { Oryctolagus } \\
\text { cuniculus }\end{array}$ & XP_002712030 & na & na & 784 & $7: 9,175,391-9,196,368$ & $19(+\mathrm{ve})$ & 20,978 & 88,047 & na & 6.5 & 79 & 29 & 22 \\
\hline Panda & $\begin{array}{l}\text { Ailuropoda } \\
\text { melanoleuca }\end{array}$ & XP_002924225 & na & na & 738 & *193114:349,706-368,327 & $19(+v e)$ & 18,622 & 83,365 & na & 7.9 & 79 & 31 & 22 \\
\hline Opossum & $\begin{array}{l}\text { Monodelphis } \\
\text { domestica }\end{array}$ & XP_001364826 & na & na & 768 & $8: 205,592,264-205,612,188$ & $18(-\mathrm{ve})$ & 19,925 & 86,352 & na & 6.3 & 55 & 27 & 21 \\
\hline \multicolumn{15}{|l|}{ MME } \\
\hline Human & Homo sapiens & NM_000902 & BC101632 & P08473 & 750 & $3: 154,801,957-154,898,245$ & $22(+\mathrm{ve})$ & 96,289 & 85,514 & 4.3 & 5.5 & 21 & 36 & 100 \\
\hline \multicolumn{15}{|l|}{ ECE1 } \\
\hline Human & Homo sapiens & NM_004826 & BC050453 & 095672 & 775 & $2: 233,344,866-233,351,363$ & $17(-\mathrm{ve})$ & 6,498 & 87,791 & 0.4 & 6.6 & 30 & 100 & 36 \\
\hline
\end{tabular}

Table 1: Mammalian KEL and human ECE1 and MME genes and proteins.

RefSeq: the reference amino acid sequence; 'predicted Ensembl amino acid sequence; na-not available; GenBank IDs are derived NCBI http://www.ncbi.nIm.nih.gov/ genbank/; Ensembl ID was derived from Ensembl genome database http://www.ensembl.org ; UNIPROT refers to UniprotKB/Swiss-Prot IDs for individual endopeptidaselike proteins (see http://kr.expasy.org); *refers to an unknown scaffold; bps refers to base pairs of nucleotide sequences; pl refers to theoretical isoelectric points; the number of coding exons are listed; high \% identities are shown in bold; high gene expression levels are in bold; (a) and (b) refer to isoform sequences for human KELL. 
Citation: Holmes RS (2013) Evolution of Mammalian KELL Blood Group Glycoproteins and Genes (KEL): Evidence for a Marsupial Origin from an Ancestral M13 Type II Endopeptidase Gene. J Phylogen Evolution Biol 1: 112. doi:10.4172/2329-9002.1000112

Page 3 of 9

\begin{tabular}{|c|c|c|c|c|c|c|c|c|c|c|c|}
\hline Gene KELL & Species & $\begin{array}{l}\text { RefSeq ID } \\
\text { 'EnsembI/NCBI }\end{array}$ & GenBank ID & UNIPROT ID & $\begin{array}{l}\text { Amino } \\
\text { Acids }\end{array}$ & Chromosome location & $\begin{array}{l}\text { Coding Exons } \\
\text { (strand) }\end{array}$ & \begin{tabular}{|l} 
Gene \\
Size bps
\end{tabular} & $\begin{array}{l}\text { Subunit } \\
\text { MW }\end{array}$ & $\begin{array}{l}\text { Gene } \\
\text { Expression }\end{array}$ & pl \\
\hline Human & Homo sapiens & NM_001113347 & BC117256 & P42892 & 770 & $1: 21,546,451-21,616,907$ & $19(-\mathrm{ve})$ & 70,457 & 87,163 & 4.4 & 5.6 \\
\hline Mouse & Mus musculus & NM_199307 & AB060648 & Q4PZA2 & 769 & $4: 137,469,641-137,518,818$ & $18(+v e)$ & 49,178 & 87,085 & 3.7 & 5.6 \\
\hline Chicken & Gallus gallus & NM_204717 & AF98287 & Q9DGN6 & 752 & $21: 6,600,258-6,607,612$ & $17(+\mathrm{ve})$ & 7,355 & 84,986 & na & 5.1 \\
\hline Zebrafish & Danio rerio & NP_001071260 & BC125952 & F1RAS8 & 752 & $11: 28,797,446-28,829,975$ & $18(-v e)$ & 32,530 & 85,206 & na & 5.8 \\
\hline \multicolumn{12}{|l|}{ ECE2 } \\
\hline Human & Homo sapiens & NM_014693 & BC005835 & 060344 & 883 & $3: 183,967,483-184,010,023$ & 19 (+ve) & 42,451 & 99,773 & 1.4 & 5.0 \\
\hline Mouse & Mus musculus & NM_177940 & BC115541 & B2RQR8 & 881 & $16: 20,611,698-20,645,306$ & 19 (+ve) & 33,609 & 99,480 & 1.0 & 5.0 \\
\hline Chicken & Gallus gallus & ${ }^{1} X P \_003641814$ & na & F1NW61 & 768 & $9: 15,356,256-15,361,432$ & $19(-v e)$ & $\# 5,177$ & 86,536 & na & 5.1 \\
\hline Zebrafish & Danio rerio & ${ }^{1} \mathrm{XP} \_00133328$ & na & na & 759 & $15: 4,034,811-4,106,595$ & $19(-\mathrm{ve})$ & 71,785 & 85,699 & na & 5.0 \\
\hline \multicolumn{12}{|l|}{ MME } \\
\hline Human & Homo sapiens & NM_000902 & BC101632 & P08473 & 750 & $3: 154,801,957-154,898,245$ & $22(+v e)$ & 96,289 & 85,514 & 4.3 & 5.5 \\
\hline Mouse & Mus musculus & NM_008604 & BC034092 & Q61391 & 750 & $3: 63,040,057-63,184,251$ & $22(+v e)$ & 80,195 & 85,702 & 2.0 & 5.6 \\
\hline Turkey & Meleagris gallopavo & ${ }^{1} X P \_003209305$ & na & G1NEB9 & 751 & $11: 23,284,588-23,318,940$ & $22(-\mathrm{ve})$ & 34,353 & 85,530 & na & 5.5 \\
\hline Puffer fish & $\begin{array}{l}\text { Tetraodon } \\
\text { nigroviridis }\end{array}$ & ${ }^{1}$ ENSTNIP00000010506 & na & $\mathrm{H} 3 \mathrm{CQH} 2$ & 750 & $16: 2,485,166-2,501,356$ & $22(+v e)$ & 16,191 & 86,039 & na & 5.7 \\
\hline \multicolumn{12}{|l|}{ MMEL1 } \\
\hline Human & Homo sapiens & NM_033467 & BC032051 & Q495T6 & 779 & $1: 2,522,432-2,560,923$ & $23(-v e)$ & 38,492 & 89,367 & 0.5 & 5.6 \\
\hline Mouse & Mus musculus & NM_013783 & AF157105 & Q9JLI3 & 765 & $4: 154,245,762-154,269,331$ & $23(+v e)$ & 23,570 & 88,700 & 0.3 & 6.1 \\
\hline Chicken & Gallus gallus & ${ }^{1} \mathrm{XP} \_001233077$ & na & na & 745 & $21: 1,388,408-1,409,376$ & $22(+\mathrm{ve})$ & 20,969 & 85,614 & na & 5.6 \\
\hline Zebrafish & Danio rerio & ${ }^{1} X P \_689191$ & na & na & 755 & $11: 42,025,785-42,081,241$ & $22(+v e)$ & 55,457 & 86,770 & na & 5.4 \\
\hline \multicolumn{12}{|l|}{ ECEL1 } \\
\hline Human & Homo sapiens & NM_004826 & BC050453 & 095672 & 775 & $2: 233,344,866-233,351,363$ & $17(-\mathrm{ve})$ & 6,498 & 87,791 & 0.4 & 6.6 \\
\hline Mouse & Mus musculus & NM_0213306 & BC057569 & Q9JMI0 & 775 & $1: 89,044,565-89,051,564$ & $17(-\mathrm{ve})$ & 7,000 & 87,993 & 0.7 & 7.9 \\
\hline Chicken & Gallus gallus & ${ }^{1} X P \_422744$ & na & F1NKL6 & 763 & $9: 15,047,449-15,053,456$ & $17(-\mathrm{ve})$ & 6,008 & 87,744 & na & 6.5 \\
\hline Tetraodon & $\begin{array}{l}\text { Tetraodon } \\
\text { nigroviridis }\end{array}$ & 'ENSTNIT00000017527 & na & H3C5L5 & 776 & $16: 6,933,748-6,943,633$ & $18(-\mathrm{ve})$ & 9,886 & 89,111 & na & 6.9 \\
\hline \multicolumn{12}{|l|}{ PHEX } \\
\hline Human & Homo sapiens & NM_000444 & BC105057 & P78562 & 749 & $X: 22,051,124-22,266,067$ & $22(+v e)$ & 214,944 & 86,474 & 0.6 & 8.9 \\
\hline Mouse & Mus musculus & NM_011077 & EF194891 & A2ICR0 & 749 & $X: 153,600,106-153,852,688$ & $22(-\mathrm{ve})$ & 252,583 & 86,359 & 0.3 & 9.0 \\
\hline Chicken & Gallus gallus & NM_001199277 & na & E1BXR4 & 751 & $1: 118,329,962-118,421,519$ & $22(-\mathrm{ve})$ & 91,558 & 87,146 & na & 9.2 \\
\hline Zebrafish & Danio rerio & NM_001089349 & BC139673 & F1R6K1 & 745 & $24: 26,230,575-26,253,987$ & $22(+v e)$ & 23,413 & 85,271 & na & 7.1 \\
\hline \multicolumn{12}{|l|}{ NEP22 } \\
\hline Worm & $\begin{array}{c}\text { Caenorhabitis } \\
\text { elegans }\end{array}$ & NM_077127 & na & Q22763 & 798 & $X: 9,034,601-9,038,311$ & $12(+v e)$ & 3,711 & 88,549 & na & 5.2 \\
\hline
\end{tabular}

Table 2: Vertebrate ECEL1, ECE1, ECE2, MME, MMEL1 and PHEX genes and proteins.

RefSeq: the reference amino acid sequence; ${ }^{1}$ predicted Ensembl amino acid sequence; na-not available; GenBank IDs are derived NCBI http://www.ncbi.nlm.nih.gov/ genbank/; EnsembI ID was derived from Ensembl genome database http://www.ensembl.org ; UNIPROT refers to UniprotKB/Swiss-Prot IDs for individual endopeptidaselike proteins (see http://kr.expasy.org); bps refers to base pairs of nucleotide sequences; pl refers to theoretical isoelectric points; the number of coding exons are listed; high gene expression levels are in bold.

\section{Results and Discussion}

\section{Alignments of mammalian KELL amino acid sequences}

The deduced amino acid sequences for gibbon (Nomascus leucogenys), horse (Equus caballus) and rat (Rattus norvegicus) KELL proteins are shown in Figure 1, together with previously reported sequences for human [2] and mouse KELL proteins [9] (Table 1). Alignments of human with other mammalian sequences examined were between $55-98 \%$ identical, suggesting that these are members of the same gene family, whereas comparisons of sequence identities of mammalian KELL proteins with human ECE1 and MME proteins exhibited lower levels of sequence identities: $27-31 \%$ and $19-22 \%$, respectively, indicating that these are members of distinct M13 Type II endopeptidase-like gene families (Table 1).

The amino acid sequences for mammalian KELL proteins contained between 713 (for human KELL isoform 'b') and 784 (for rabbit KELL) residues, whereas most mammalian KELL sequences contained either 732 amino acids (for human KELL isoform 'a'), or 713 residues (for human KELL isoform 'b') (Figure 1; Table 1). Previous studies have reported several key regions and residues for human and mouse KELL proteins (human isoform ' $b$ ' KELL amino acid residues were identified in each case). These included an $\mathrm{N}$-terminus cytoplasmic tail (residues
1-28), followed by a hydrophobic transmembrane twenty residue segment, which may anchor the enzyme to the plasma membrane [2]. These $\mathrm{N}$-terminal cytoplasmic tail and transmembrane regions revealed a high degree of amino acid sequence conservation (Figure 1). This region was further characterized by conserved 'book-end' residues for mammalian KELL, Arg27-Arg/Trp28 at the N-terminal end, and Tyr48 at the C-terminal end of the membrane anchoring segment, which may contribute to the membrane spanning properties. Figure 2 provides an alignment of the cytoplasmic $\mathrm{N}$-terminal sequences for several mammalian KELL sequences, including human KELL 'a' and ' $b$ ' isoform sequences. These contained identical transmembrane and endopeptidase domains, but with $\mathrm{N}$-terminal cytoplasmic domains of different lengths (residues 1-47 and 1-24 for the human ' $a$ ' and ' $b$ ' isoforms, respectively). This explains the differences in amino acid composition for these human KELL proteins (732 and 713 amino acids, respectively). Figure 2 also shows $\mathrm{N}$-terminal cytoplasmic domain sequences for other mammalian cytoplasmic domain KELL sequences, including rabbit KELL, which contained an extended N-terminal cytoplasmic domain sequence of 99 amino acid residues.

Residues 49-713 of the human KELL sequence were identified using bioinformatics as a large peptidase family M13 endopeptidaselike domain involved in the proteolysis of peptides in the body [47]. 
Citation: Holmes RS (2013) Evolution of Mammalian KELL Blood Group Glycoproteins and Genes (KEL): Evidence for a Marsupial Origin from an Ancestral M13 Type II Endopeptidase Gene. J Phylogen Evolution Biol 1: 112. doi:10.4172/2329-9002.1000112

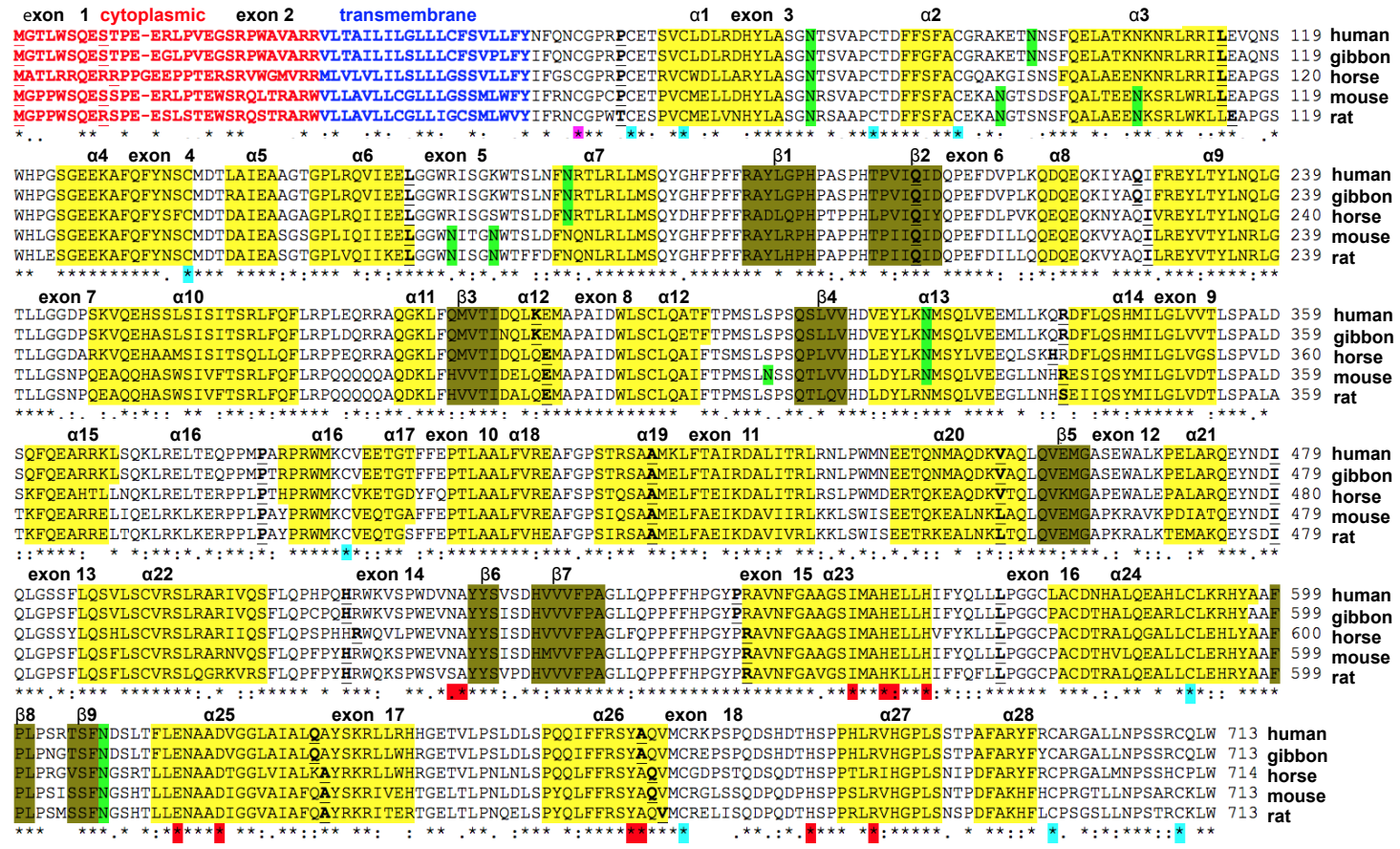

Figure 1: Amino acid sequence alignments for mammalian KELL sequences

See Table 1 for sources of KELL sequences; *shows identical residues for KELL subunits; : similar alternate residues; . dissimilar alternate residues; predicted cytoplasmic residues are shown in red; predicted transmembrane residues are shown in blue; $\mathrm{N}$-glycosylated and potential $\mathrm{N}$-glycosylated Asn sites are in green; endopeptidase active site residues are shown in red; three predicted Zinc-binding residues are also shown in red; conserved Cys53, forming a disulfide bond with $\mathrm{XY}$ protein is shown in pink; conserved Cys residues that align with MME disulfide bond forming Cys residues are in blue; predicted $\alpha$-helices for vertebrate KELL are in shaded yellow, and numbered in sequence from the start of the predicted transmembrane domain; predicted $\beta$-sheets are in shaded green, and also numbered in sequence from the $\mathrm{N}$-terminus; bold underlined font shows residues corresponding to known or predicted exon start sites; exon numbers refer to human $K E L$ gene exons; note the three major domains identified as cytoplasmic (N-terminal tail); transmembrane (for linking KELL to the cell membrane); and extracellular domains.

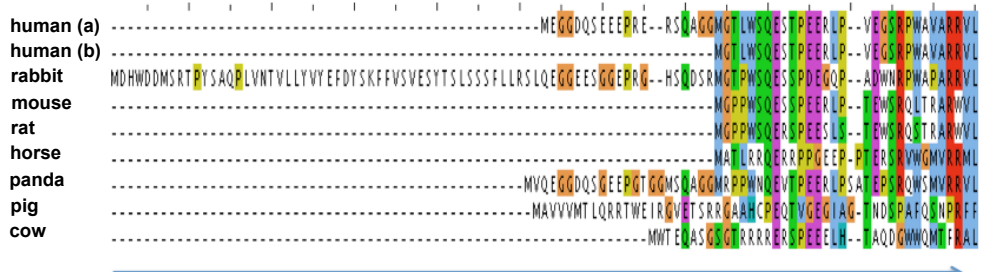

\section{KELL $\mathbf{N}$-terminal cytoplasmic domain}

Figure 2: Amino acid sequence alignments for mammalian KELL cytoplasmic domain sequences

Amino acids are color coded: yellow for proline (P); S (serine); green for hydrophilic amino acids, S (serine), Q (glutamine), N (asparagine), and T (threonine); brown for glycine (G); light blue for hydrophobic amino acids, L (leucine), I (isoleucine), V (valine), M (methionine), W (tryptophan); dark blue for amino acids, T (tyrosine) and $\mathrm{H}$ (histidine); purple for acidic amino acids, $\mathrm{E}$ (glutamate) and D (aspartate); and red for basic amino acids, K (lysine) and R (arginine); the N-terminus (cytoplasmic) domain is identified; human (a) and (b) refer to major KELL isoform sequences.

This C-terminal region is predicted to be localized extracellularly, and to contain an active M13-like endopeptidase sequence capable of metabolizing physiologically active peptides. Four (horse and pig KELL sequences) to eight (mouse KELL sequence) $\mathrm{N}$-glycosylation sites were predicted for the mammalian KELL sequences examined, which shared 16 distinct $\mathrm{N}$-glycosylation sites (Figure 1; Table 3). Most mammalian KELL sequences exhibited at least four common N-glycosylation sites, designated as sites $1,10,13$ and 16 (Table 3 ). It is relevant to note that a high frequency human KEL polymorphism (site 10, Table 3) is responsible for removing an $\mathrm{N}$-glycosylation site, resulting in the synthesis of antigens $\mathrm{K}_{1}$ and $\mathrm{K}_{2}$ with distinct antigenic properties [27,32]. This lends support to a significant role being played by at least this N-glycosylation site in contributing to the structure and antigenic properties of this protein.
Twelve active site residues were conserved for the mammalian KELL sequences examined (Figure 1; Supplementary Table 1s; Figure 1 ), which are deduced from the M13 peptidase domain active site residues reported for the NCBI domain studies [47]. These included an active site catalytic residue (Glu563); an active site proton donor (Asp619); 3 residues involved in binding the active site Zinc (His562, His566 and Glu615), deduced from 3D studies of a related enzyme, MME [14]; and 7 other active site residues, also deduced from the MME tertiary structure, namely Asn521, Ala522, Ile599, Tyr658, Ala659, His675 and Arg681 (Figure 1; Supplementary Table 1s). Of particular significance, however, was the amino acid substitution observed for the KELL 'active site' Glu563 residue, which was replaced by a basic amino acid (lysine) for the rat and rabbit KELL sequences. This is likely to have 
Citation: Holmes RS (2013) Evolution of Mammalian KELL Blood Group Glycoproteins and Genes (KEL): Evidence for a Marsupial Origin from an Ancestral M13 Type II Endopeptidase Gene. J Phylogen Evolution Biol 1: 112. doi:10.4172/2329-9002.1000112

Page 5 of 9
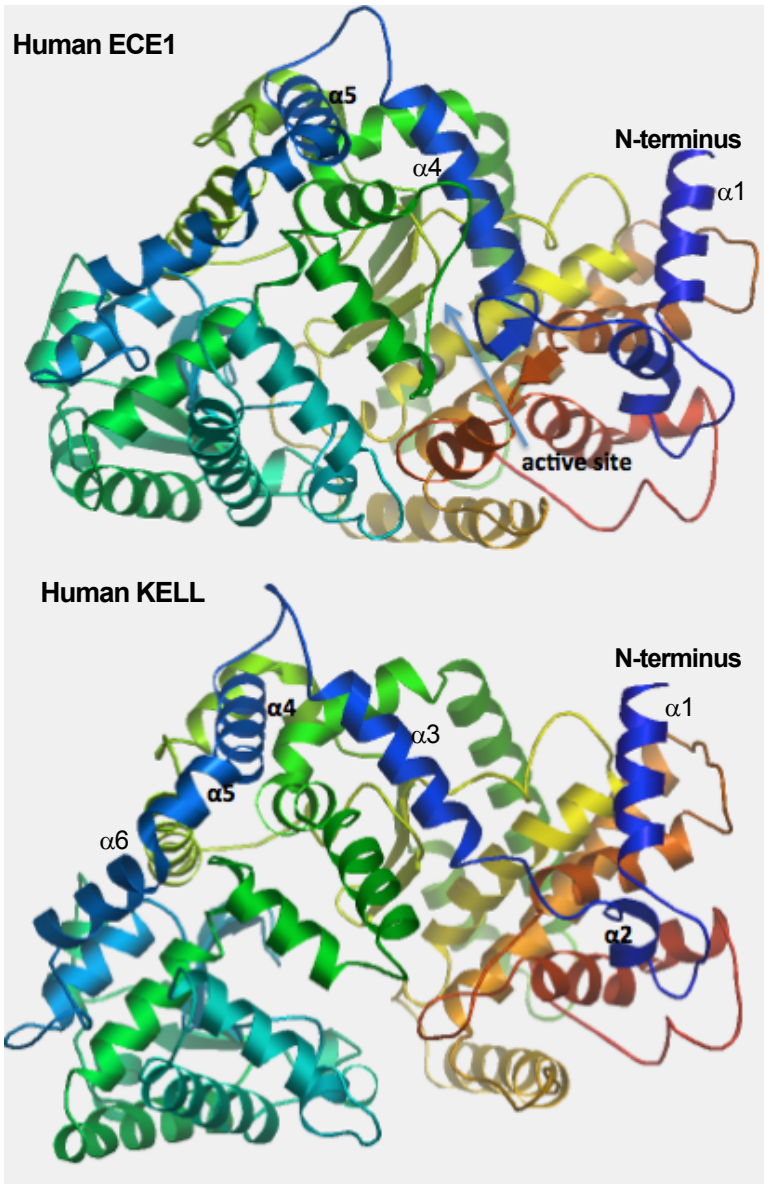

Figure 3: Comparisons of the known tertiary structure for human ECE1 with the predicted structure for human KELL.

The structure for the human ECE1 subunit and the predicted structure for the human KELL subunit are based on the reported structure for human ECE1 [20], and obtained using the SWISS MODEL web site based on PDB 3dwbA http:// swissmodel.expasy.org/workspace/ The rainbow color code describes the 3-D structures from the $\mathrm{N}$ - (blue) to C-termini (red color); predicted $\alpha$-helices, $\beta$-sheets and proposed active site cleft are shown. a major impact on the endopeptidase activity for these proteins and may reflect a 'null' phenotype for rat and rabbit KELL proteins, similar to that observed for the human $\mathrm{K}_{0}$ KELL variant phenotype [33]. Most of the other residues in the active site and C-terminal KELL regions were predominantly conserved for many of the mammalian KELL proteins examined, which may reflect strong functional roles for these sequences as well (Figure 1).

There were several conserved Cys residues among the mammalian KELL sequences examined, including Cys53 (Figure 1), which forms a heterodimeric disulfide bond with the XK red cell membrane protein, a multipass transport protein [8]. Ten other Cys residues were conserved among the mammalian KELL sequences examined, which aligned with 10 of 12 Cys residues reported as forming disulfide bonds for the human MME sequence [53]. These included the following potential disulfide bond positions for human KELL: Cys58-Cys63; Cys81Cys698; Cys89-Cys663; Cys136-Cys391; and Cys591-Cys729, which suggests that mammalian KELL proteins contain five disulfide bonds in similar positions to those reported for five of the six human MME disulfide bonds [53], in addition to the disulfide bond linking KELL with the XK red cell membrane protein [8].

Alignments of the C-terminal sequences for human, opossum and tasmanian devil (Sarcophilus harrisii), KELL proteins are shown in Supplementary Figure 1s, together with the corresponding KEL 3 nucleotide sequences. In contrast to all other mammalian C-terminal KELL sequences examined, the opossum KELL sequence contained three additional amino acids (Leu-Ser-Ala) to the C-terminal Trp residue observed for all other mammalian KELL sequences. It is likely that mutations in this region of the ancestral opossum KEL sequence may have caused a shift of the stop codon downstream, with a corresponding extension of the C-terminal opossum KELL sequence.

\section{Predicted secondary and tertiary structures for mammalian KELL proteins}

Predicted secondary structures for human, mouse, gibbon, horse and rat KELL sequences were examined, particularly for the extracellular sequences (Figure 1), using the known structure reported for an M13 family peptidase, human ECE1 [20]. $\alpha$-Helix and $\beta$-sheet structures were identical in each case, with $28 \alpha$-helices and $9 \beta$-sheet structures being observed. Of particular interest were $\alpha$-helices 23,25 ,

\begin{tabular}{|c|c|c|c|c|c|c|c|c|c|c|c|c|c|c|c|c|c|}
\hline Endopeptidase & Site 1 & Site 2 & Site 3 & Site 4 & Site 5 & Site 6 & Site 7 & Site 8 & Site 9 & Site 10 & Site 11 & Site 12 & Site 13 & Site 14 & Site 15 & Site 16 & $\begin{array}{l}\text { Total No } \\
\text { of sites }\end{array}$ \\
\hline KELL & & & & & & & & & & & & & & & & & of Sites \\
\hline Human & 75NTSV & & & & 96NNSF & & & & & 172NRTL & & & 326NMSQ & & & 608NDSL & 5 \\
\hline Chimpanzee & 75NTSV & & & & 96NNSF & & & & & 172NQTL & & & 326NMSQ & & & 608NDSL & 5 \\
\hline Gorilla & 75NTSV & & & & 96NNSF & & & & & 172NRTL & & & 326NMSQ & & & 608NDSL & 5 \\
\hline Gibbon & 75NTSV & & & & 96NNSF & & & & & 172NRTL & & & 326NMSQ & & 603NGTS & 608NDSL & 6 \\
\hline Rhesus & 75NTSV & & & & & & & & 165NWTS & 172NRTL & & & 326NMSQ & & & 608NDSL & 5 \\
\hline Squirrel monkey & 75NTSV & & & & 96NTSF & & & & 165NWTS & 172NRTL & & & 326NMSQ & & & 608NDSL & 6 \\
\hline Mouse & 75NRSV & 93NGTS & & & & 106NKSR & & 161NITG & 165NWTS & & & 311NSSQ & 326NMSQ & & & 608NGSH & 8 \\
\hline Rat & 75NRSA & 93NGTS & & & & 106NKSR & & 161NISG & 165NWTF & & & & 326NMSQ & & & 608NGSH & 7 \\
\hline Cow & 84NTSV & 102NRTG & & & & & 147NMSA & & & 181NQTL & & & 334NMSQ & & & 616NVSR & 6 \\
\hline Horse & 75NTSV & & & & & & & & & 172NRTL & & & 326NMSY & & & 608NGSR & 4 \\
\hline Pig & & 110NRTR & & & & & & & & 189NQTL & & & 343NMSR & & & 625NGSY & 4 \\
\hline Rabbit & & 164NGTS & & & & 177NKSR & & & 236NWTS & 243NQTL & & & 397NMSQ & & 679NGTS & & 6 \\
\hline Panda & 100NTSV & & & & & & & & 190NWTS & 197NRTL & & & 351NMSQ & & 628NGTF & 633NGSR & 6 \\
\hline Opossum & 124NASA & & 140NLTS & 147NESR & & & & & & 226NHTL & 275NYTQ & & & 419NLSQ & & & 6 \\
\hline
\end{tabular}

Table 3: Predicted N-Glycosylation sites for mammalian KELL sequences.

Amino acids are represented as N (asparagine), P (proline); S (serine); Q (glutamine), T (threonine); G (glycine); L (leucine), I (isoleucine), V (valine), M (methionine), W (tryptophan); H (histidine); E (glutamate); D (aspartate); K (lysine) and R (arginine); sites are numbered in sequence from the $\mathrm{N}$-terminus. 
Citation: Holmes RS (2013) Evolution of Mammalian KELL Blood Group Glycoproteins and Genes (KEL): Evidence for a Marsupial Origin from an Ancestral M13 Type II Endopeptidase Gene. J Phylogen Evolution Biol 1: 112. doi:10.4172/2329-9002.1000112

Page 6 of 9

26 and 27, which contained several predicted active site residues for human KELL. A predicted tertiary structure for human KELL is shown in Figure 3, together with human ECE1 [20]. The tertiary structure of the extracellular domain (residues 60-713) for human KELL was similar to that described for human ECE1 [20]. Twenty-eight $\alpha$-helices and nine $\beta$-sheet structures were observed, which is similar to that described for the predicted secondary structure for this enzyme. In addition, two major domains for these enzymes were observed, that enclose a large cavity previously shown to contain the enzyme's active site. The more C-terminal of these two domains has been shown to have a fold similar to that of thermolysin which contains the active site residue, whereas the other domain may serve to control access of substrates to the active site [20]. Overall, the predicted human KELL structure closely resembled that reported for human ECE1 [20], and MME [14]. Previous modeling studies have reported that the human KELL protein contains two globular domains, consisting mostly of $\alpha$-helices, with the domain situated closest to the transmembrane sequence containing both the $\mathrm{N}$-and C-terminal sequences and the active site [54]. In addition, the outer domain of the protein contained all of the amino acids involved in forming at least 30 human KELL antigenic sites.

\section{Gene locations, exonic structures and regulatory sequences for mammalian $K E L$ genes}

Table 1 summarizes the predicted locations for mammalian $K E L$ genes based upon BLAT interrogations of several mammalian genomes, using the reported sequences for human [2] and mouse [9], KELL and the predicted sequences for other mammalian KELL proteins and the UC Santa Cruz genome browser [44]. The mammalian KEL genes examined were transcribed on the minus strand. Figure 1 summarizes the predicted exonic start sites for human, mouse, gibbon, horse and rat KEL genes, based on the KELL ' $b$ ' isoform, with each having 18 coding exons, in identical or similar positions to those predicted for the human KEL gene.

Figure 4 shows the predicted structures for the major human and mouse KEL transcripts. In each case, two major transcripts were observed, including the reference sequences (NM_000420 and NM_032540), which were 2811 and 2531 bps in length, with extended 5'- and 3'-untranslated regions (UTR), for the human and mouse KEL transcripts. The two major human $K E L$ transcript isoforms, designated as ' $a$ ' and 'b', encode proteins with distinct N-terminal amino acid sequences, and contain 732 and 713 amino acids with 19 and 18 coding exons, respectively (Table 1; Figure 2) [28]. The human KEL promoter region does not contain a TATA box, but has potential transcription factor binding sites for GATA-1 and Sp1 [29], as well as several other KEL promoter transcription factor binding sites (Table 4). Of particular significance to KEL gene regulation for erythroid cell development are the following sites: NF-E2: a transcriptional factor essential for erythroid maturation and differentiation, which also participates in the transcriptional activation of the mammalian beta-globin gene locus [55]; GATA1: a transcriptional activator localized in the promoters of the globin gene family and other erythroid-specific genes [56]; and EVI1: a transcription activator which is essential for the proliferation and maintenance of hematopoietic stem cells [57]. It would appear that the KEL gene promoter is well endowed with gene regulatory sequences, which may contribute to the high levels of $K E L$ expression in mammalian erythroid cells, and to the maintenance of this expression during development.

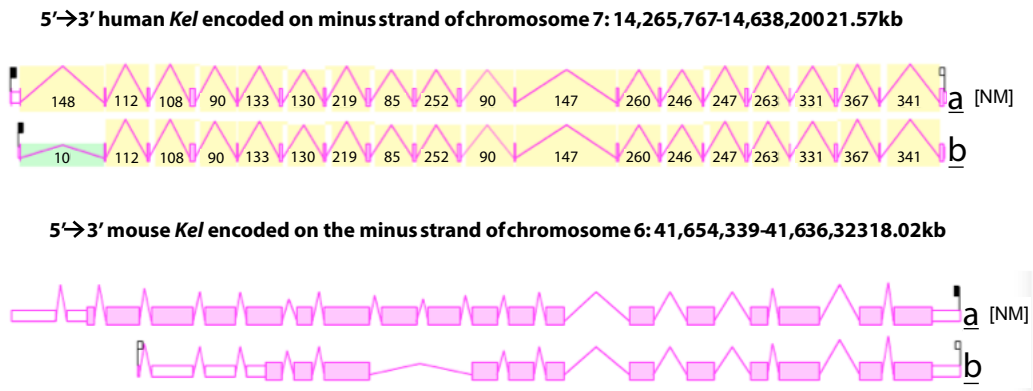

Figure 4: Gene structure and major gene transcripts for the human KEL and mouse $K e /$ genes

Derived from the AceView website http://www.ncbi.nIm.nih.gov/IEB/Research/Acembly/ [28]; shown with capped 5'- and 3'- ends for the two isoform mRNA sequences, in each case; NM refers to the NCBI reference sequence; exons are in pink; the direction for transcription is shown as $5^{\prime} \rightarrow 3^{\prime}$; numbers within the human intron sequences refer to bps.

\begin{tabular}{|c|c|c|c|c|c|c|}
\hline TFBS & Name & Strand & Chr 7 Position & Function/Role & Sequence & UNIPROT ID \\
\hline NFE2 & Transcription factor NF-E2 & $(-\mathrm{ve})$ & $142,661,722-142,662,732$ & $\begin{array}{l}\text { Essential for regulating erythroid } \\
\text { maturation and differentiation }\end{array}$ & TGATGACTCAC & Q16621 \\
\hline $\mathrm{BACH} 2$ & $\begin{array}{l}\text { Transcription regulator } \\
\text { protein } \mathrm{BACH} 2\end{array}$ & $(+v e)$ & $142,661,721-142,661,731$ & Transcriptional regulator & GGTGAGTCATC & Q9BYV9 \\
\hline GATA1 & Erythroid transcription factor & $(-v e)$ & $142,661,694-142,661,706$ & $\begin{array}{l}\text { Transcriptional activator acting as a } \\
\text { general switch for erythroid development }\end{array}$ & GGGTGATAAGAAG & P15976 \\
\hline FOXJ2 & Forkhead box protein J2 & $(+\mathrm{ve})$ & $142,660,952-142,660,965$ & Transcriptional activator & ACAATAATATCTAA & Q9P0K8 \\
\hline EVI1 & $\begin{array}{l}\text { MDS1 and EVI1 complex } \\
\text { locus protein EVI1 }\end{array}$ & $(+v e)$ & $142,660,943-142,660,958$ & $\begin{array}{l}\text { Transcriptional regulator involved in } \\
\text { hematopoiesis }\end{array}$ & TGGCAAGATACAATAA & P14404 \\
\hline EVI1 & $\begin{array}{l}\text { MDS1 and EVI1 complex } \\
\text { locus protein EVI1 }\end{array}$ & (-ve) & $142,659,507-142,659,522$ & $\begin{array}{c}\text { Transcriptional regulator involved in } \\
\text { hematopoiesis }\end{array}$ & TGAGAAGCTGAGATAA & P14404 \\
\hline TLX2 & $\begin{array}{l}\text { T-cell leukemia homeobox } \\
\text { protein } 2\end{array}$ & $(-v e)$ & $142,658,874-142,658,883$ & $\begin{array}{l}\text { Transcriptional activator that binds DNA } \\
\text { via its homeobox }\end{array}$ & AGGTAAGTGG & Q9UQ48 \\
\hline
\end{tabular}

Table 4: Identification of Transcription Factor Binding Sites (TFBS) within the Human KEL gene promoter.

The identification of $K E L$ TFBS within the KEL promoter region was undertaken using the human genome browser (http://genome.ucsc.edu); UNIPROT refers to UniprotKB/ Swiss-Prot IDs for individual TFBS sequences (http://kr.expasy.org). 


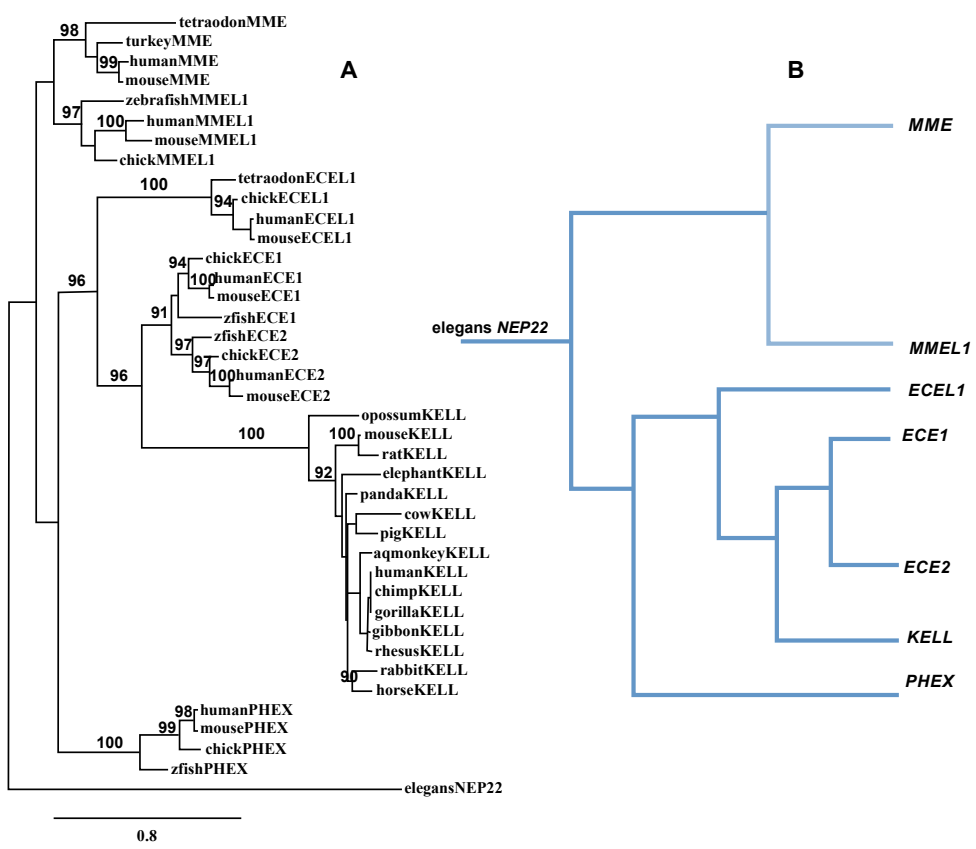

Figure 5: Phylogenetic tree of mammalian KELL amino acid sequences with representative vertebrate MME, MMEL1, ECE1, ECE2, ECEL1 and PHEX sequences.

The tree is labelled with the endopeptidase-like name and the name of the animal and is 'rooted' with the worm (Caenorhabditis elegans) NEP22 sequence, which was used to 'root' the tree. Note the 5 major groups corresponding to the MME and MMEL1; PHEX; ECEL1; KEL; and ECE1 and ECE2 gene families. A genetic distance scale is shown. The number of times a clade (sequences common to a node or branch) occurred in the bootstrap replicates are shown. Only replicate values of 90 or more, which are highly significant, are shown with 100 bootstrap replicates performed in each case. A proposed sequence of gene duplication events is shown arising from an ancestral endopeptidase-like gene.

\section{KEL tissue expression}

Supplementary Figure 2 presents 'heat maps' showing comparative KEL expression in various human tissues obtained from GNF Expression Atlas 2 Data using U133A and GNF1H (human) chips (http://genome.ucsc.edu; http://biogps.gnf.org) [48]. These data supported high level tissue expression for human KEL, particularly in bone marrow (BM) erythroid cells, which is consistent with previous reports for this gene [5-7]. Another study reported that the KELL protein is expressed in nonerythroid tissues, including testis and skeletal muscle, although KEL transcripts were also reported in several other tissues [3]. Supplementary Figure 2 supports this wider KEL tissue expression, particularly for testis and fetal liver. Overall, human KEL and mouse Kel tissue expression levels were 0.5-0.8 times the average level of gene expression which supports a key role for this protein as an endopeptidase, but with a highly specific erythroid tissue expression profile $[5-7,28]$.

\section{Phylogeny and divergence of mammalian KEL and other vertebrate M13 type II endopeptidase genes and proteins}

A phylogenetic tree (Figure 5) was calculated by the progressive alignment of 15 mammalian KELL amino acid sequences with several other vertebrate M13 type II endopeptidase-like sequences, which was 'rooted' with the worm (Caenorhabditis elegans) membrane metallopeptidase (NEP22) sequence Table 1 and 2). The phylogram showed clustering of the KELL sequences into groups consistent with their evolutionary relatedness, as well as groups for each of the vertebrate M13 type II endopeptidase families, which were distinct from the worm NEP22 sequence. These groups were significantly different from each other (with bootstrap values $>90$ ). This data suggests that the KEL gene and KELL protein have appeared early in marsupial and eutherian mammalian evolution, for which a proposed common ancestor for these genes may have predated or coincided with the appearance of marsupial mammals during vertebrate evolution. The KEL gene (and KELL protein) was apparently absent from monotreme (platypus: Ornithorhynchus anatinus), bird (chicken: Gallus gallus), reptile (lizard: Anolis carolensis), amphibian (frog: Xenopus tropicalis) and fish (zebrafish: Danio rerio) genomes, whereas other vertebrate M13 type II endopeptidase genes (MME, MMEL1, ECE1, ECE2, ECEL1 and $P H E X$ ) were present throughout vertebrate evolution (Figure 5) [57]. In addition, these results suggested that the mammalian KEL gene evolved, following a gene duplication event of an ECE-like gene, given that ECE1, $E C E 2$ and KEL appear to be more closely related to each other, than to other M13 type II endopeptidase genes. This is consistent with a recent study of the evolution of vertebrate ECEL1 genes and proteins [57].

\section{Conclusions}

This study suggests that mammalian KEL genes and encoded KELL proteins represent a distinct gene and protein family of M13 Type II neutral endopeptidase-like proteins which share conserved sequences, and active site residues with those reported for other related M13 Type II endopeptidases, MME, MMEL1, ECE1, ECE2, ECEL1 and PHEX, previously studied [19-22,25,58]. KELL has a distinctive property among these M13 Type II neutral endopeptidases in serving as a major RBC antigen and blood group within human populations [2,5-7]. In addition, KELL is capable of processing 'big' endothelin-3, generating endothelin-3 (ET-3), which is a potent bioactive peptide capable of acting as a vasoconstrictor [10]. KELL 'null' variants, however, exist naturally in human populations without apparent major health impact $[31,34,35]$. Moreover, the mammalian active site Glu563 residue is substituted in rat and rabbit KELL proteins by a lysine residue (Supplementary Table 1s), which may reflect a more substantial role for KELL as a RBC blood group antigen rather than as an active endopeptidase. 
Citation: Holmes RS (2013) Evolution of Mammalian KELL Blood Group Glycoproteins and Genes (KEL): Evidence for a Marsupial Origin from an Ancestral M13 Type II Endopeptidase Gene. J Phylogen Evolution Biol 1: 112. doi:10.4172/2329-9002.1000112

KELL is encoded by a single gene (KEL), among the marsupial and eutherian mammalian genomes studied, which is highly expressed in human and mouse erythroid cells and usually contained 18 or 19 coding exons on the negative strand. Several transcription factor binding sites were localized within the human KEL gene promoter region, including GATA1, EVI1 and NFE2, which are essential in regulating erythroid cell differentiation and maintenance of expression, and may contribute significantly to the high level of gene expression in bone marrow erythroid cells.

Predicted secondary and tertiary structures for vertebrate KELL proteinsshowed a strong similarity with other M13 typeII endopeptidaselike proteins. Several major structural domains were apparent for mammalian KELL proteins, including a $\mathrm{N}$-terminal cytoplasmic tail of varying lengths between human KELL isoforms and other mammalian KELL sequences; a transmembrane domain which anchors the enzyme to the cell membrane; and an extracellular domain, containing the active site (including a zinc binding site), which is responsible for endopeptidase activity; and four conserved N-glycosylation sites, which may contribute significantly to the antigenic properties for this blood group protein. Several KELL endopeptidase domain cysteine residues were conserved among mammalian sequences, including Cys53 (see Figure 1), which forms a heterodimeric disulfide bond with the XK red cell membrane protein, a multipass transport protein [8]. Ten other Cys residues were also conserved which aligned with 10 of 12 Cys residues forming disulfide bonds for the human MME sequence [53]. This suggests that mammalian KELL proteins may contain five disulfide bonds in similar positions to those reported for five of the six human MME disulfide bonds [53]. Alternatively, these Cys residues may serve other KELL structural or functional roles.

A phylogenetic study used 15 mammalian KELL sequences with a range of other vertebrate M13 type II endopeptidase sequences, which indicated that the KEL gene had appeared early in marsupial mammalian evolution, prior to or coincident with the appearance of marsupial mammals, and existed as a distinct gene family within this group, together with the MME and MMEL1; ECE1 and ECE2; ECEL1; and PHEX gene groups. Moreover, the study indicated that the KEL gene may have originated from a gene duplication event of an ancestral mammalian ECE-like gene, in common with the ECE1 and ECE2 genes, which originated much earlier in vertebrate evolution, as both of these genes have been reported in bird, reptile, amphibian and fish genomes [57].

\section{References}

1. Rawlings ND, Barrett AJ (1993) Evolutionary families of peptidases. Biochem J 290: 205-218.

2. Lee ME, Temizer DH, Clifford JA, Quertermous T (1991) Cloning of the GATAbinding protein that regulates endothelin-1 gene expression in endothelial cells. J Biol Chem 266: 16188-16192.

3. Russo D, Wu X, Redman CM, Lee S (2000) Expression of Kell blood group protein in nonerythroid tissues. Blood 96: 340-346.

4. Bland ND, Pinney JW, Thomas JE, Turner AJ, Isaac RE (2008) Bioinformatic analysis of the neprilysin (M13) family of peptidases reveals complex evolutionary and functional relationships. BMC Evol Biol 8: 16.

5. Reid ME, Mohandas N (2004) Red blood cell blood group antigens: structure and function. Semin Hematol 41: 93-117.

6. Mohandas N, Narla A (2005) Blood group antigens in health and disease. Curr Opin Hematol 12: 135-140.

7. Dean L (2005) The Kell blood group. In: Blood Groups and Red Cell Antigens, Chapter 8, National Center for Biotechnology Information, Bethesda MD, USA.

8. Russo D, Redman C, Lee S (1998) Association of XK and Kell blood group proteins. J Biol Chem 273: 13950-13956.
9. Lee S, Russo DC, Pu J, Ho M, Redman CM (2000) The mouse Kell blood group gene (Kel): cDNA sequence, genomic organization, expression, and enzymatic function. Immunogenetics 52: 53-62.

10. Lee S, Lin M, Mele A, Cao Y, Farmar J, et al. (1999) Proteolytic processing of big endothelin-3 by the kell blood group protein. Blood 94: 1440-1450.

11. Clapéron A, Rose C, Gane P, Collec E, Bertrand O, et al. (2005) The Kell protein of the common $\mathrm{K} 2$ phenotype is a catalytically active metalloprotease whereas the rare Kell K1 antigen is inactive. Identification of novel substrates for the Kell protein. J Biol Chem 280: 21272-21283.

12. Letarte M, Vera S, Tran R, Addis JB, Onizuka RJ, et al. (1988) Common acute lymphocytic leukemia antigen is identical to neutral endopeptidase. J Exp Med 168: $1247-1253$.

13. Shipp MA, Richardson NE, Sayre PH, Brown NR, Masteller EL, et al. (1988) Molecular cloning of the common acute lymphoblastic leukemia antigen (CALLA) identifies a type II integral membrane protein. Proc Natl Acad Sci U S A 85: 4819-4823.

14. Oefner C, D'Arcy A, Hennig M, Winkler FK, Dale GE (2000) Structure of human neutral endopeptidase (Neprilysin) complexed with phosphoramidon. J Mol Biol 296: 341-349.

15. Bonvouloir N, Lemieux N, Crine P, Boileau G, DesGroseillers L (2001) Molecular cloning, tissue distribution, and chromosomal localization of MMEL2 a gene coding for a novel human member of the neutral endopeptidase-24.11 family. DNA Cell Biol 20: 493-498.

16. Hirschfield GM, Liu X, Han Y, Gorlov IP, Lu Y, et al. (2010) Variants at IRF5TNPO3, 17q12-21 and MMEL1 are associated with primary biliary cirrhosis. Nat Genet 42: 655-657.

17. Ban M, McCauley JL, Zuvich R, Baker A, Bergamaschi L, et al. (2010) A nonsynonymous SNP within membrane metalloendopeptidase-like 1 (MMEL1) is associated with multiple sclerosis. Genes Immun 11: 660-664.

18. Danoy P, Wei M, Johanna H, Jiang L, He D, et al. (2011) Association of variants in MMEL1 and CTLA4 with rheumatoid arthritis in the Han Chinese population. Ann Rheum Dis 70: 1793-1797.

19. Schmidt M, Kröger B, Jacob E, Seulberger H, Subkowski T, et al. (1994) Molecular characterization of human and bovine endothelin converting enzyme (ECE-1). FEBS Lett 356: 238-243.

20. Schulz H, Dale GE, Karimi-Nejad Y, Oefner C (2009) Structure of human endothelin-converting enzyme I complexed with phosphoramidon. J Mol Biol 385: 178-187.

21. Lorenzo MN, Khan RY, Wang Y, Tai SC, Chan GC, et al. (2001) Human endothelin converting enzyme-2 (ECE2): characterization of mRNA species and chromosomal localization. Biochim Biophys Acta 1522: 46-52.

22. Mzhavia N, Pan H, Che FY, Fricker LD, Devi LA (2003) Characterization of endothelin-converting enzyme-2. Implication for a role in the nonclassical processing of regulatory peptides. J Biol Chem 278: 14704-14711.

23. Valdenaire O, Richards JG, Faull RL, Schweizer A (1999) XCE, a new member of the endothelin-converting enzyme and neutral endopeptidase family, is preferentially expressed in the CNS. Brain Res Mol Brain Res 64: 211-221.

24. Schweizer A, Valdenaire O, Köster A, Lang Y, Schmitt G, et al. (1999) Neonatal lethality in mice deficient in XCE, a novel member of the endothelin-converting enzyme and neutral endopeptidase family. J Biol Chem 274: 20450-20456.

25. Du L, Desbarats M, Viel J, Glorieux FH, Cawthorn C, et al. (1996) cDNA cloning of the murine Pex gene implicated in X-linked hypophosphatemia and evidence for expression in bone. Genomics 36: 22-28.

26. Miao D, Bai X, Panda D, McKee M, Karaplis A, et al. (2001) Osteomalacia in hyp mice is associated with abnormal phex expression and with altered bone matrix protein expression and deposition. Endocrinology 142: 926-939.

27. Lee S, Zambas E, Green ED, Redman C (1995) Organization of the gene encoding the human Kell blood group protein. Blood 85: 1364-1370.

28. Thierry-Mieg D, Thierry-Mieg J (2006) AceView: A comprehensive cDNAsupported gene and transcripts annotation. Genome Biol 7: S12.

29. Redman CM, Lee S (1995) The Kell blood group system. Transfus Clin Biol 2 243-249.

30. Lee S, Wu X, Son S, Naime D, Reid M, et al. (1996) Point mutations characterize KEL10, the KEL3, KEL4, and KEL21 alleles, and the KEL17 and KEL11 alleles. Transfusion 36: 490-494. 
Citation: Holmes RS (2013) Evolution of Mammalian KELL Blood Group Glycoproteins and Genes (KEL): Evidence for a Marsupial Origin from an Ancestral M13 Type II Endopeptidase Gene. J Phylogen Evolution Biol 1: 112. doi:10.4172/2329-9002.1000112

31. Zhu X, Rivera A, Golub MS, Peng J, Sha Q, et al. (2009) Changes in red cell ion transport, reduced intratumoral neovascularization, and some mild moto function abnormalities accompany targeted disruption of the Mouse Kell gene (Kel). Am J Hematol 84: 492-498.

32. Lee S, Wu X, Reid M, Redman C (1995) Molecular basis of the K:6,-7 [Js(a+b-)] phenotype in the Kell blood group system. Transfusion 35: 822-825.

33. Lee S, Debnath AK, Wu X, Scofield T, George T, et al. (2006) Molecular basis of two novel high-prevalence antigens in the Kell blood group system, KALT and KTIM. Transfusion 46: 1323-1327.

34. Yu LC, Twu YC, Chang CY, Lin M (2001) Molecular basis of the Kell-nul phenotype: a mutation at the splice site of human KEL gene abolishes the expression of Kell blood group antigens. J Biol Chem 276: 10247-10252.

35. Yang Y, Wang L, Wang C, Chen H, Guo Z, et al. (2009) Two novel null alleles of the KEL gene detected in two Chinese women with the K(null) phenotype. Transfus Med 19: 235-244.

36. Hoffman JF, Joiner W, Nehrke K, Potapova O, Foye K, et al. (2003) The hSK4 (KCNN4) isoform is the Ca2+-activated $\mathrm{K}+$ channel (Gardos channel) in human red blood cells. Proc Natl Acad Sci U S A 100: 7366-7371.

37. Tuson M, Hue-Roye K, Koval K, Imlay S, Desai R, et al. (2011) Possible suppression of fetal erythropoiesis by the Kell blood group antibody anti-Kp(a). Immunohematology 27: 58-60.

38. Altschul SF, Gish W, Miller W, Myers EW, Lipman DJ (1990) Basic loca alignment search tool. J Mol Biol 215: 403-410.

39. Guo R, Quarles LD (1997) Cloning and sequencing of human PEX from a bone cDNA library: Evidence for its developmental stage-specific regulation in osteoblasts. J Bone Miner Res 12: 1009-1017.

40. Grieff M, Mumm S, Waeltz P, Mazzarella R, Whyte MP, et al. (1997) Expression and cloning of the human X-linked hypophosphatemia gene cDNA. Biochem Biophys Res Commun 231: 635-639.

41. Dixon PH, Christie PT, Wooding C, Trump D, Grieff M, et al. (1998) Mutationa analysis of PHEX gene in X-linked hypophosphatemia. J Clin Endocrinol Metab 83: $3615-3623$.

42. Kiryu-Seo S, Sasaki M, Yokohama H, Nakagomi S, Hirayama T, et al. (2000) Damage-induced neuronal endopeptidase (DINE) is a unique metallopeptidase expressed in response to neuronal damage and activates superoxide scavengers. Proc Natl Acad Sci U S A 97: 4345-4350.

43. Benoit A, Vargas MA, Desgroseillers L, Boileau G (2004) Endothelin-converting enzyme-like 1 (ECEL1) is present both in the plasma membrane and in the endoplasmic reticulum. Biochem J 380: 881-888.
44. Kent WJ, Sugnet CW, Furey TS, Roskin KM, Pringle TH, et al. (2002) The human genome browser at UCSC. Genome Res 12: 996-1006.

45. Schwede T, Kopp J, Guex N, Peitsch MC (2003) SWISS-MODEL: An automated protein homology-modeling server. Nucleic Acids Res 31: 3381-3385.

46. Krogh A, Larsson B, von Heijne G, Sonnhammer EL (2001) Predicting transmembrane protein topology with a hidden Markov model: Application to complete genomes. J Mol Biol 305: 567-580

47. Marchler-Bauer A, Lu S, Anderson JB, Chitsaz F, Derbyshire MK, et al. (2011) CDD: a Conserved Domain Database for the functional annotation of proteins. Nucleic Acids Res 39: D225-D229.

48. Su Al, Wiltshire T, Batalov S, Lapp H, Ching KA, et al. (2004) A gene atlas of the mouse and human protein-encoding transcriptomes. Proc Natl Acad Sci U S A 101: 6062-6067.

49. Dereeper A, Guignon V, Blanc G, Audic S, Buffet S, et al. (2008) Phylogeny fr: Robust phylogenetic analysis for the non-specialist. Nucleic Acids Res 36 W465-W469.

50. Edgar RC (2004) MUSCLE: A multiple sequence alignment method with reduced time and space complexity. BMC Bioinformatics 5: 113.

51. Guindon S, Gascuel O (2003) A simple, fast, and accurate algorithm to estimate large phylogenies by maximum likelihood. Syst Biol 52: 696-704.

52. Oefner C, Roques BP, Fournie-Zaluski MC, Dale GE (2004) Structural analysis of neprilysin with various specific and potent inhibitors. Acta Crystallogr D Bio Crystallogr 60: 392-396.

53. Lee S, Debnath AK, Redman CM (2003) Active amino acids of the Kell blood group protein and model of the ectodomain based on the structure of neutral endopeptidase 24.11. Blood 102: 3028-3034.

54. Shyu YC, Lee TL, Ting CY, Wen SC, Hsieh LJ, et al. (2005) Sumoylation of p45/NF-E2: nuclear positioning and transcriptional activation of the mammalian beta-like globin gene locus. Mol Cell Biol 25: 10365-10378.

55. Trainor CD, Evans T, Felsenfeld G, Boguski MS (1990) Structure and evolution of a human erythroid transcription factor. Nature 343: 92-96.

56. Shimabe M, Goyama S, Watanabe-Okochi N, Yoshimi A, Ichikawa M, et al. (2009) Pbx1 is a downstream target of Evi-1 in hematopoietic stem/progenitors and leukemic cells. Oncogene 28: 4364-4374.

57. Holmes RS, Cox LA (2013) Comparative studies of vertebrate endothelinconverting enzyme-like 1 genes and proteins. Res Rep Biochemistry 3: 1-16. 